\title{
Double the Trouble?: An Investigation of How Social Stressors and Time Pressure Simultaneously and Interdependently Predict Sleep Quality in Social Workers
}

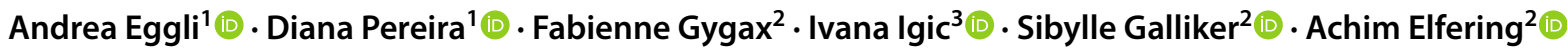

Received: 15 April 2021 / Revised: 5 August 2021 / Accepted: 19 January 2022 / Published online: 11 February 2022

(c) The Author(s) 2022

\begin{abstract}
Purpose Social service employees often fulfill their mandate under tight time schedules, and deal with social stressors. This can result in significant health impairments. By means of one cross-sectional and two intensive longitudinal studies, the present paper aimed to understand how time pressure and social stressors might impact sleep quality. It was also tested whether social stressors amplified the negative association between time pressure and sleep impairments in social workers. Methods Study 1 was a cross-sectional questionnaire study on 52 social service employees, while study 2 included a 7-day diary study design ( $N=62$ social workers) with up to 138 daily measurements. Study 3 applied a 2-week diary and actigraphy assessment, involving a complete social service unit sample $(N=9)$.

Results Concerning the moderating role of social stressors, study 1 found social stressors to amplify the effects of time pressure on sleep latency. Multilevel regression analyses of studies 2 and 3 revealed daily time pressure to be a significant predictor of sleep fragmentation the upcoming night. Study 3 further uncovered daily social stressors to positively predicted sleep fragmentation and negatively sleep duration. Study 2 again showed the amplifying interaction effect between daily social stressors and time pressure on sleep fragmentation, but study 3 did not show that interaction.

Conclusion The findings show how job stressors might disturb the sleep quality of social workers also with amplifying risk. Accordingly, social work needs work design prevention efforts that consider the complex inter-play between occupational stressors, as only then recovery processes can be protected.
\end{abstract}

Keywords Social stressors $\cdot$ Time pressure $\cdot$ Sleep actigraphy $\cdot$ Sleep quality

Andrea Eggli

andrea.eggli@bfh.ch

Diana Pereira

diana.romano@bfh.ch

Fabienne Gygax

fabienne.gygax@students.unibe.ch

Ivana Igic

ivana.igic@ispw.unibe.ch

Sibylle Galliker

sibylle.galliker@sigall.ch

Achim Elfering

achim.elfering@psy.unibe.ch

1 Department of Social Work, Bern University of Applied Sciences, 3012 Bern, Switzerland

2 Institute of Psychology, University of Bern, 3012 Bern, Switzerland

3 Department of Health Science \& Institute of Psychology, University of Bern, 3012 Bern, Switzerland

\section{Introduction}

Research in social work has increasingly focused on the crucial role that sleep plays in clients' lives [1]. Social workers are encouraged to promote clients' sleep quality to support counseling interventions [2]. But what about the sleep quality of social workers themselves? The profession's nature makes it vulnerable to severe work-related stressors, resulting in serious health consequences [3] and threatens the social service mandate [4].

\subsection{Time Pressure and Social Stressors in Social Work}

Time pressure is a heightened job demand, defined as the extent to which employees feel they need to work faster than usual or lack enough time to complete tasks [5]. Such time pressure is typical in social services due to staff shortages 
and heavy caseloads, and administrative tasks that need to be completed in a constrained timeframe or otherwise require overtime [6]. Time pressure can have beneficial effects (e.g., eliciting motivational energy). Nonetheless, many studies from different occupational disciplines have linked it to adverse consequences, like reduced work engagement and exhaustion [7-9]. However, empirical knowledge on the daily intrapersonal effects of time pressure on sleep remains sparse.

Parallel to time pressures, social service employees often face social stressors: characteristics, situations, episodes, or behaviors that are related to psychological and physical strain and are of a social nature (e.g., conflicts with co-workers and supervisors, unfair behaviors) [10, 11]. For social service providers, collaborations with supervisors and coworkers can be challenging because of the complexity of their discussions (e.g., workload distribution and handling of complex cases) [6]. According to the Stress-as-Offense-toSelf (SOS) theory [12], social stressors at work may hinder the establishment and maintenance of a positive self-image, thus provoking stress reactions and health impairments [13]. Indeed, past studies found social stressors related to various adverse health outcomes, such as depression, attention failure, and poor sleep quality $[10,14,15]$. A diary study by Eggli et al. [16] even found social stressors from supervisors to anteceded more daily physical symptoms in social workers.

Yet, what is striking, is that past studies have isolated these two job stressors to examine their cross-sectional and within-subject effects on well-being. Sonnentag [17] critically argues that by having done so, the interdependencies between these job stressors has been overlooked; hence, the possibility that time pressure and social stressors interact in their prediction of health outcomes has not been considered. Especially complex recovery processes, such as sleep, are likely to be influenced by potential amplifying interaction effects of job stressors [17].

\subsection{Physiological Sleep Quality as an Indicator for Health Impairments}

It has already been established that stress represents a significant threat to sleep [18], which can induce further physical and psychological health impairments [15]. The theories of effort recovery [19] and allostatic load [20] explain that since work-related stressors are effortful for employees, they create short-term physiological and psychological reactions (e.g., accelerated heart rate) [19]. Usually, after having spent time off work, the psychobiological system stabilizes and acute reactions to stress are reversed [19, 21]. However, particularly stressful job incidences (e.g., social stressors and time pressure) [15] may elongate psychophysiological load reactions and thus threaten recovery, resources, as well as sleep [19, 22]. In support of this notion, numerous cross-sectional and ambulatory studies found social stressors to harm sleep quality [15, 21, 23-26]. Additionally, other occupational stressors, such as the number of patient interactions and working hours, have been found to impair sleep indicators [27-29]. For Sonnentag [17], the fact that sleep is impaired when job stressors are high is paradoxical, as the experience of exactly such high stressors would call for effective recovery processes to set in (i.e., good sleep); she terms this phenomenon 'the recovery paradox'.

Prior research has revealed that whether or not sleep impairments occur, may also depend on the type of job stressor being witnessed [17]. While daily intrapersonal stressors (e.g., social stressors) seem to strongly influence sleep quality [15, 21, 23-26], this seems to be less likely for high quantitative job demands (e.g., time pressure) [17]. Yet, realistically speaking, social workers do not only witness a single type of stressor in the span of their working day, but also face different job stressors coincidental. Exactly these concurrencies may amplify the effects on sleep quality indicators; hence, time pressure may only become particularly harmful for sleep, under high social stressor conditions. Indeed, a few prior studies have found such moderating interaction effects between time pressure and social stressors [e.g., 30, 31].

Identifying amplifying effect models is key, to enable the safeguarding of sleep and diminishing the recovery paradox [17]. Only if sleep can be secured and preserved, then recovery from occupational strain is guaranteed for social workers [32], as sleep reduces biological (i.e., hibernation) and mental functions, which in turn conserves energy and builds resources beyond what is attainable during wakefulness $[33,34]$.

\subsection{Purpose of the Present Study}

Evidently, sleep is a key resource for social workers recovery and well-being [17]. However, this valuable recovery process is compromised by the precise job stressors, it should actually be buffering at work. The aim of the present study is to (a) understand how social stressors and time pressure impact sleep quality, and (b) uncover whether the interdependency between time pressure and social stressors determine sleep impairment in social workers, and in broader terms help to understand the "recovery paradox".

It was thus hypothesized that time pressure and social stressors, as multiple predictors, will positively relate to sleep fragmentation (i.e., sleep disturbances and difficulties staying asleep; Hypothesis 1), sleep latency (i.e., difficulties falling asleep; Hypothesis 2), and negatively to sleep duration (i.e., problems waking up too early; Hypothesis $3)$. Furthermore, the present paper postulates that social stressors will amplify the impact of time pressure on sleep 
fragmentation (Hypothesis 4), sleep latency (Hypothesis 5) and sleep duration (Hypothesis 6).

To ensure a highly comprehensive evaluation of this research question, the present paper analyzed three distinctive social worker samples, all collected by means of different research designs: (a) Study 1 encompassed a cross-sectional analysis, (b) study 2 was a 7-day diary investigation, and (c) study 3 incorporated a diary and actigraphy research design.

Upon closer inspection of past research, it becomes clear that most studies relied solely on self-report assessments [i.e., 7-10, 16]. Thus, they are prone to common-method bias, social desirability, and self-serving bias [35, 36]. Only a few actigraphy studies exist, which, however, often sampled employees of different organizational and occupational settings [e.g., 15, 36]; thus, there is a sampling bias risk [37]. Study 3 tackled these limitations, by applying a diary and actigraphy research design with a complete social service unit sample.

Furthermore, the present study particularly acknowledged that the effects of job demands may be distinctive for the various sleep indicators. For instance, Pereira et al. [15, 21] has repeatedly revealed that the intrapersonal effects of social stressors corresponded to sleep fragmentation, but not other sleep parameters (e.g., sleep-onset latency, sleep efficiency). Noteworthy, Wesensten et al., 38] reported that sleep fragmentation reduces recuperation independent of the total sleep duration. Accordingly, studies 1 to 3 investigated the effects on various sleep indicators.

\section{Subjects and methods}

The research questions were investigated in three independent samples (i.e., studies 1-3). The methodological procedures and samples will be explained in the following sections.

\subsection{Procedure and Sample}

Study 1 Data collection was conducted in 2020 with the JobStress-Index (JSI) assessment, as part of a joint project by Health Promotion Switzerland, Zurich University of Applied Sciences, and the University of Bern [39]. Data were drawn from the LINK Internet-Panel, the largest online panel in Switzerland with more than 130,000 active members. The sample included employees from the German-, French- and Italian-speaking parts of Switzerland. From the complete dataset, baseline measurements of 52 social workers were extracted on time pressure, social stressors with supervisors, difficulty falling asleep, difficulties staying asleep, and problems waking up to early. The study was conducted in cooperation with a governmental health promotion organization with ethical approval. Participation in the questionnaire study was voluntary for every employee.

The sample consisted of 52 social work employees, of which 42 were female and 10 males. The mean age of participants was 44.3 years old $(\mathrm{SD}=13.12)$. Concerning educational levels, 14 (26.9\%) subjects had completed an apprenticeship, seven (13.5\%) achieved a high school diploma, and $30(57.7 \%)$ participants had attained a higher educational degree from university.

Study 2 A total of 93 Swiss social workers were recruited by means of a convenience sampling procedure in 2019. The inclusion criteria demanded participants to be employed as social workers in Switzerland and work a minimum of $40 \%$, calculated based on Swiss full-time employment. The sample consisted of 74 (79.6\%) females and 19 (20.4\%) males. On average, participants were 39.5 years of age, ranging from 23 to 62 years $(S D=10.1)$. Subjects were employed in vast social work fields, i.e., educational, and psychiatric social work, disability services, state social services and immigration assistance. The sample size on Level 2 was 62 , exceeding the recommended minimum sample size of 50 [40]. The sample size of Level 1 was 138. Owing to missing values (i.e., work-free days), the size of level 1 varies for different variables. These variations mainly occurred because participants were asked not to complete the afterwork questionnaire on work-free days, and thus only actigraphy assessments of working nights were used. No dropouts of participants were reported. The study was approved by the ethics committee of the author's affiliated university (Nr. 2010-08-00003).

All participants received an informative email about the research design and procedure. Willing subjects commenced by completing an online general questionnaire that assessed demographic and occupational variables (Level 2). Level 1 variables were then continuously assessed with two distinctive self-report questionnaires: A morning questionnaire to assess sleep quality indicators and an evening questionnaire to assess social stressors and time pressure. It was mandatory to complete both questionnaires on all working days, the morning questionnaire before starting work and the evening questionnaire post ending work.

Study 3 A sample of nine employees (eight woman and one man) was obtained from a Swiss social service organization in 2020. Two participants were between 20 and 30 years old $(22 \%)$, two in the $31-40$ years age range $(22 \%)$, three were 41-50 years old (33\%), and two lay in the range of 51-60 years (22\%). The participants' employment ranged from $50 \%$ to full-time. Four employees (44\%) worked in the administration, and five were social workers $(56 \%)$. The majority of participants $(N=6 ; 67 \%)$ indicated that they 'occasionally' did overtime in the past 30 days. On average, participants reported having worked between 1 and $10 \mathrm{~h}$ of overtime per week in the last 30 days. The participation rate 
was $100 \%$. All study participants provided informed consent, and the ethics committee of the authors' affiliated university approved the study design (Nr. 2010-08-00003).

The research design included diary and ambulatory assessments over a continuous 2 -week period. At the start, participants received an email with research information and directions on completing questionnaires and about actigraphy use. They were asked to provide informed consent and complete the general questionnaire before the diary data collection began. The following Monday, participants began a 2-week dairy study. During these 2 weeks, participants were instructed to continuously wear the SenseWear armbands and complete a self-report questionnaire every day at two points in time: after ending work and before going to bed. On work-free days, participants were instructed not to complete the after-work questionnaire.

\subsection{Materials}

Study 1 Regarding the first study, the following self-report instruments were applied for data collection.

Social stressors with supervisors Frese and Zapf's 5-item scale [41] was used to assess social stressors with supervisors (e.g., "I often argue with my supervisor."). Items were answered on a 5-point Likert scale, ranging from 1 (not at all) to 5 (absolutely). Similarly as in prior studies $[10,15$, 21], a satisfactory Cronbach's alpha was revealed $(\alpha=0.85)$. The scale's mean was $1.62(\mathrm{SD}=0.76)$.

Time pressure 4-items from the self-report version of the instrument for stress-oriented task analysis (ISTA) [42] were adapted to measure time pressure at work (e.g., How often is a fast pace of work required?). The items were answered on a 5-point Likert scale ranging from 1 (very seldom/never) to 5 (very often). The scale's Cronbach's alpha was $\alpha=0.83$, and the mean score $2.95(\mathrm{SD}=0.86)$. A recent meta-analysis supported ISTA's strong reliability in psychometric properties and validity [43].

Sleep Quality Three-items of the Insomnia Severity Index [44] were administered. The three-items (i.e., difficulty falling asleep, difficulties staying asleep and problems waking up to early) were rated on a 5-point Likert scale, ranging from 0 (none) to 4 (very). The mean scores of the indicators were 1.02 ( $\mathrm{SD}=0.96)$ for difficulties falling asleep, $1.15(\mathrm{SD}=0.96)$ for difficulties staying asleep, and 1.12 $(\mathrm{SD}=1.06)$ for problems waking up too early.

Control Variables Since sleep activity has been found to vary depending on age and gender [45], these variables were controlled for.

Studies 2 and 3 Regarding studies 2 and 3, the following research material and instruments were applied for data collection.

General Questionnaire In studies 2 and 3, before commencing with diary data collection, participants completed a general questionnaire that assessed their demographic and occupational backgrounds.

Diary In studies 2 and 3, time-based diaries assessed daily social stressors, time pressures and sleep quality indicators. Study 2 conducted a seven-day diary research design, while study 3 set a 2 -week timeframe for a diary and actigraphy investigation. Diaries were completed twice a day: after leaving the workplace and before going to sleep. The variables 'social stressors' and 'time pressure' were assessed after ending the workday, while sleep quality indicators were assessed every morning before starting work.

Social stressors A 10-item scale, developed by Frese and Zapf [41], measured interpersonal tensions (e.g., conflicts, personal animosities) with co-workers and supervisors after workdays. Items were introduced in the following way "to what extent do the following statements apply to you? Today...," and an example is "when a mistake occurred, my supervisor always pushed it on me, never on himself." Items were answered on a 5-point Likert scale, ranging from 1 (not at all) to 5 (absolutely). Regarding study 2, a Cronbach's alpha of $\alpha=0.84$ was attain, with a mean of 1.06 $(\mathrm{SD}=0.27)$. Study 3 yielded a Cronbach's alpha of $\alpha=0.64$, and the scale's mean was $1.07(\mathrm{SD}=0.14)$. Prior studies have found good Cronbach's alphas $(\alpha=0.80-0.87)$ and showed strong validity concerning job characteristics and health variables $[10,15,21]$.

Time pressure The self-report version of the instrument for stress-oriented task analysis (ISTA) [42] was adapted to measure daily time pressure at work. While study 2 applied 4 items, study 3 used 5 items (e.g., Today at work, I was under time pressure?), which were answered on a 5-point Likert scale ranging from 1 (very seldom/never) to 5 (very often). Study 2 revealed a Cronbach's alpha of $\alpha=0.87$, with a mean of $1.75(\mathrm{SD}=0.70)$. Regarding study 3 , the Cronbach's alpha was $\alpha=0.91$ and the mean score 2.48 $(\mathrm{SD}=1.02)$. In a recent meta-analysis of 51 studies, Irmer et al. [43] revealed that the ISTA has reliable psychometric properties and strong validity.

Sleep Quality Indicators Study 2 assessed sleep disturbances with one item from the German version of the Pittsburgh Sleep Quality Index (i.e., Last night I slept badly because I woke up in the middle of the night or early in the morning") [46]. The item was rated on a 5-point Likert scale, ranging from 1 (very seldom/never) to 5 (very often).

Control Variables In studies 2 and 3, age and gender (Level 2 variables) were controlled for, since prior studies had found sleep activity to differ depending on these [45].

Actigraphy Study 3 applied actigraphs for the continuous assessment of sleep quality parameters during nights. Actigraphy has received considerable attention from sleep researchers [23], based on the notion that sleep phases entail reduced movements, while wake phases indicate increased movements [47]. Each participant wore miniaturized 
computerized wristwatch-like devices (i.e., BodyMedia SenseWear armbands) for a continuous 2 -week period. Every minute, 2-axis oscillometric sensors measure body movements and other physiological reactions, such as surface body temperature, heat flux, and galvanic skin responses during the night [47]. Because SenseWear armbands are worn on the upper arm instead of the wrist, they tend to minimize extraneous movement noise [47]. A study by van Wouwe et al. [48] validated SenseWear armbands to provide specific and accurate sleep indicator predictions. The data were analyzed with BodyMedia software, which estimates sleep and wake phases using computer algorithm-defined activity thresholds [21]. The present study used three objectively assessed sleep quality indicators: sleep fragmentation, sleep latency and sleep duration. Sleep fragmentation was coded by the number of awakenings that lasted $5 \mathrm{~min}$ or longer, preceded, and followed by a minimum of $15 \mathrm{~min}$ of uninterrupted sleep [15]. Sleep latency was defined as the time participants required to fall asleep after going to bed [23]. The amount of sleep time (in minutes) until waking up represented sleep duration.

\subsection{Analysis}

In regard to studies 1, 2 and 3, all figures as well as the simple and multilevel regression analyses were performed with "The R Project for Statistical Computing [49]".

Study 1 Calculations for correlational analyses, multiple linear regression and descriptive statistics were performed using the IBM SPSS software package, version 27.0 [50]. The predictor variable (i.e., time pressure) and moderator variable (i.e., social stressors) were group-mean centered.

Study 2 and 3 For statistical analysis in studies 2 and 3, daily data (Level 1) were nested within participants (Level 2). In the multilevel regression analyses the interaction between two Level-1 predictor variables (i.e., social stressors and time pressure) was tested. Specially, both studies investigated the fixed effect model of how social stressors moderate the effects of time pressure on sleep quality indicators. The predictor variable (i.e., time pressure) and moderator variable (i.e., social stressors) were group-mean-centered, while age was grand-mean-centered. The outcome variables (i.e., sleep fragmentation, sleep disturbances, sleep latency, sleep duration) and gender, as a dichotomous variable, remained uncentered.

Study 2 had a sample size of 62 on Level 2, and 138 on Level 1. In study 3, the sample size for Level 2 was 9, and for Level 1, it ranged from 60 to 69 . Due to missing values (i.e., work-free days), the size of level 1 varies for different variables. For study 3 , measurements of approximately 6 to 10 nights were used per person. Therefore, it was advantageous that multilevel analysis allows for a varying number of observations (i.e., missing data). Two-tailed hypothesis tests were conducted, and standardized coefficients have been reported. The alpha level was 5\%.

\section{Results}

Study 1 Table 1 presents descriptive statistics and correlations. Higher time pressure corresponded to longer sleeponset latencies while higher social stressors corresponded to more frequent early awakening in the morning. Contrary to predictions (Hypothesis 1, $2 \& 3$ ), the analysis of the multiple predictor model revealed that neither social stressors nor time pressure predicted sleep quality impairments (see Table 2 for results). In line with Hypothesis 5, social stressors significantly amplified the effects of time pressure on difficulties falling asleep $(\beta=0.55, p<0.05$; see Table 2 , Model 2). This interaction is illustrated in Fig. 1. No support was found for Hypotheses 4 and 6, as there were no moderated interaction effects for the sleep outcomes 'difficulties staying asleep' (General Questionnaire $=0.33, p=$ ns.; see Table 2, Model 1) or 'problems waking up too early' (General Questionnaire $=0.25, p=$ ns.; see Table 4, Model 3).

Study 2 Descriptive statistics and correlations of the variables are shown in Table 3. Between-person correlations revealed that higher time pressure and social stressors

Table 1 Study 1: Descriptive statistics and correlations of variables

\begin{tabular}{|c|c|c|c|c|c|c|c|c|c|c|}
\hline Variable & $M$ & SD & $N$ & 1 & 2 & 3 & 4 & 5 & 6 & 7 \\
\hline 1. Sex ${ }^{a}$ & 1.19 & 0.40 & 47 & & & & & & & \\
\hline 2. Age & 43.91 & 13.25 & 47 & 0.03 & & & & & & \\
\hline 3. Time pressure & 3.02 & 0.86 & 47 & 0.18 & 0.03 & & & & & \\
\hline 4. Social Stressors with supervisors & 1.62 & 0.76 & 47 & $0.23 *$ & -0.01 & $0.38^{* *}$ & & & & \\
\hline 5. Difficulties staying asleep & 1.15 & 0.96 & 52 & 0.08 & $0.24 *$ & 0.16 & 0.15 & & & \\
\hline 6. Difficulties falling asleep & 1.02 & 0.96 & 52 & -0.01 & 0.13 & $0.25^{*}$ & 0.15 & $0.68^{* *}$ & & \\
\hline 7. Problem waking up too early & 1.12 & 1.06 & 52 & 0.06 & 0.06 & 0.22 & $0.32 * *$ & $0.58 * *$ & $0.62 * *$ & \\
\hline
\end{tabular}

${ }^{*} p<0.05, * * p<0.01, * * * p<0.001$, two-tailed

${ }^{\mathrm{a}} 1=$ female, $2=$ male 
Table 2 Study 1: results of multiple linear regression models

\begin{tabular}{|c|c|c|c|c|c|c|}
\hline \multirow[b]{4}{*}{ Variables } & \multicolumn{6}{|c|}{ Fixed effects } \\
\hline & \multicolumn{2}{|c|}{ Model 1} & \multicolumn{2}{|l|}{ Model 2} & \multicolumn{2}{|c|}{ Model 3} \\
\hline & \multicolumn{2}{|c|}{$\begin{array}{l}\text { Difficulties staying } \\
\text { asleep (Sleep frag- } \\
\text { mentation) }\end{array}$} & \multicolumn{2}{|c|}{$\begin{array}{l}\text { Difficulties falling } \\
\text { asleep (Sleep latency) }\end{array}$} & \multicolumn{2}{|c|}{$\begin{array}{l}\text { Problems waking } \\
\text { up too early }\end{array}$} \\
\hline & Coeff & SE & Coeff & SE & Coeff & SE \\
\hline Intercept & 0.14 & 0.67 & 0.53 & 0.64 & 0.81 & 0.71 \\
\hline Time pressure & 0.14 & 0.18 & 0.31 & 0.18 & 0.16 & 0.19 \\
\hline Social stressors with supervisors & 0.00 & 0.23 & -0.12 & 0.22 & 0.30 & 0.25 \\
\hline Time Pressure:Social Stressors & 0.33 & 0.25 & $0.55^{*}$ & 0.24 & 0.25 & 0.26 \\
\hline $\operatorname{Sex}^{\mathrm{a}}$ & 0.13 & 0.38 & -0.09 & 0.36 & -0.02 & 0.40 \\
\hline Age & 0.02 & 0.01 & 0.01 & 0.01 & 0.01 & 0.01 \\
\hline
\end{tabular}

$N=47$

${ }^{*} p<0.05, * * p<0.01, * * * p<0.001$, two-tailed

${ }^{\mathrm{a}} 0=$ female, $1=$ male

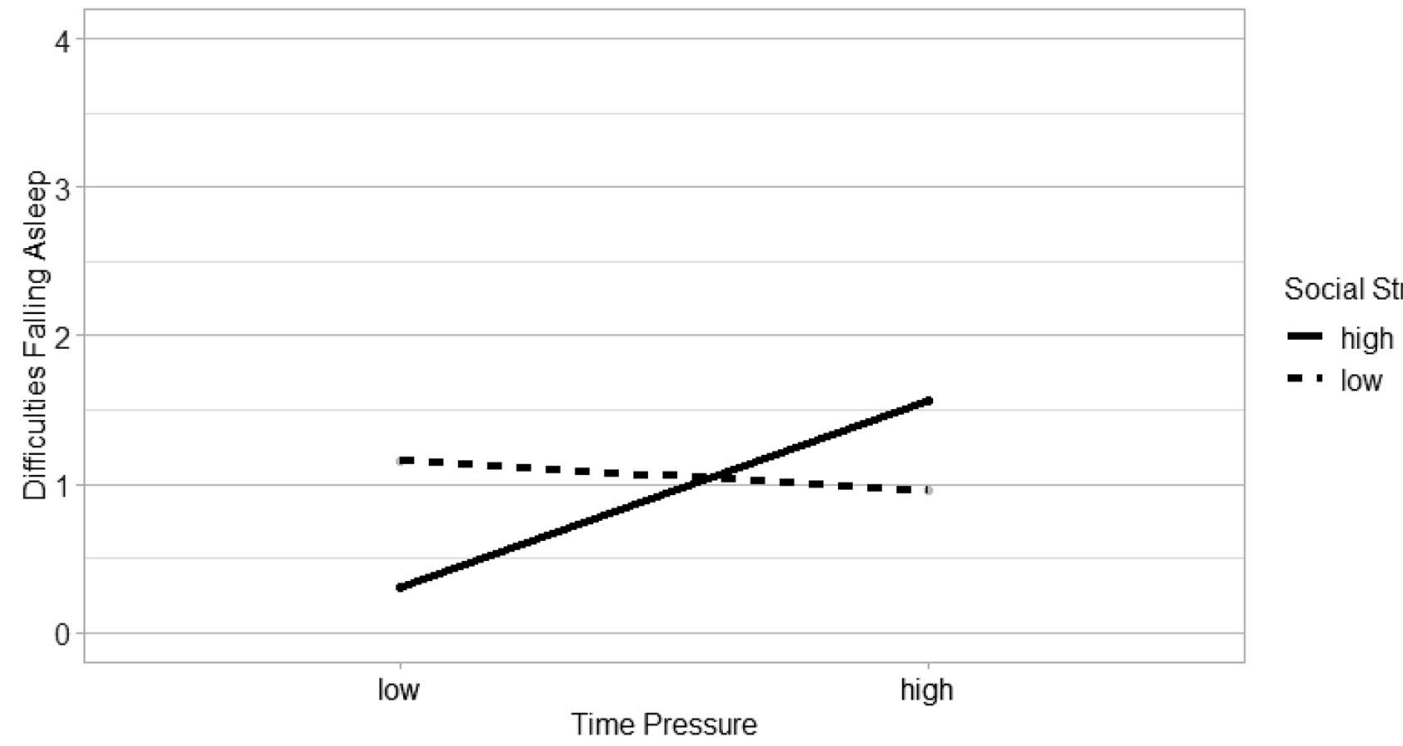

Fig. 1 Moderating Interaction Effect of Social Stressors with Super-

falling asleep in situations of high vs. low social stressor incidences. visors on the Time Pressure and Difficulties Falling Asleep RelationSample size $N=47$ situations ship. The Diagram illustrates the effect of time pressure on difficulties

Table 3 Study 2: descriptive statistics and correlations of variables

\begin{tabular}{|c|c|c|c|c|c|c|c|c|}
\hline Variable & $M$ & SD & $N$ & 1 & 2 & 3 & 4 & 5 \\
\hline 1. $\mathrm{Sex}^{\mathrm{a}}$ & 0.20 & 0.41 & 93 & & $0.35 * *$ & $-0.18 * *$ & -0.06 & -0.00 \\
\hline 2. Age & 39.19 & 10.107 & 93 & $0.35 * * *$ & & $-0.16^{* *}$ & -0.03 & $0.14 * *$ \\
\hline 3. Time pressure & 1.75 & 0.70 & 163 & 0.02 & -0.06 & & $0.36^{* *}$ & $-0.16^{* *}$ \\
\hline $\begin{array}{l}\text { 4. Social Stressors with } \\
\text { supervisors }\end{array}$ & 1.06 & 0.27 & 290 & 0.04 & -0.02 & $0.45 * * *$ & & $-0.09 *$ \\
\hline 5. Sleep Disturbances & 2.09 & 1.42 & 500 & -0.01 & $0.09^{*}$ & -0.15 & -0.07 & \\
\hline
\end{tabular}

Lower Triage $=$ Within-person Correlations

Upper Triage $=$ Between-person Correlations $* p<0.05, * * p<0.01, * * * p<0.001$, two-tailed

${ }^{\mathrm{a}} 1=$ female, $2=$ male 
Table 4 Study 2: fixed effects estimates and standard errors for the predictor models

\begin{tabular}{|c|c|c|c|c|}
\hline \multirow[b]{4}{*}{ Variables } & \multicolumn{4}{|c|}{ Fixed effects } \\
\hline & \multicolumn{2}{|l|}{ Model 1} & \multicolumn{2}{|l|}{ Model 2} \\
\hline & \multicolumn{4}{|c|}{ Predictors of sleep disturbances } \\
\hline & Coeff & SE & Coeff & SE \\
\hline Intercept & $2.07 * * *$ & 0.11 & $1.98 * * *$ & 0.18 \\
\hline \multicolumn{5}{|l|}{ Level 1} \\
\hline Time pressure ${ }^{b}$ & & & $0.23 *$ & 0.11 \\
\hline Social stressors at work ${ }^{\mathrm{b}}$ & & & 0.07 & 0.10 \\
\hline Time Pressure:Social Stressors & & & $0.15^{*}$ & 0.07 \\
\hline \multicolumn{5}{|l|}{ Level 2} \\
\hline $\operatorname{Sex}^{\mathrm{a}}$ & & & 0.22 & 0.38 \\
\hline Age & & & 0.00 & 0.02 \\
\hline
\end{tabular}

$N$ Level $1=138, N$ Level $2=62$

${ }^{*} p<0.05, * * p<0.01, * * * p<0.001$, two-tailed

${ }^{\mathrm{a}} 0=$ female, $1=$ male

${ }^{b}$ of the previous day

negatively corresponded to sleep disturbances. Prior to hypothesis testing, an intercept-only-model was calculated to estimate the proportion of variance in sleep disturbance that is accounted for the day (Level 1) and person (Level 2) levels [51]. For sleep disturbances, an ICC of 0.91 was obtained for Level 2 and 1.11 for Level 1, indicating that $45 \%$ of the variance is within-person variance (see Table 4, Model 1 ).

Multilevel analysis of the predictor model showed that daily time pressure positively predicted sleep disturbances the upcoming night, thus partially supporting hypothesis $1(\gamma=0.23, p<0.05$; see Table 4, Model 2). No significant interaction effect was found between social stressors and sleep disturbances $(\gamma=0.07, p=$ ns.; see Table 5, Model 2). It was further revealed that social workers experienced more sleep disturbances the upcoming night if daily social stressors were high during time pressure incidences $(\gamma=0.15, p<0.05$; see Table 4, Model 2); yielding support for hypothesis 4 . This interaction is illustrated in Fig. 2.

Study 3 Table 5 provides the descriptive statistics and correlations of study 3. Between-person correlations showed that higher time pressure and social stressors corresponded to more sleep fragmentation, sleep latency and sleep duration. Before testing our hypotheses, we calculated a null model to estimate the proportion of variance in sleep fragmentation, sleep latency and sleep duration that is accounted for the day (Level 1) and person (Level 2) levels [51]. Sleep fragmentation's obtained estimates of 0.29 for Level 2 and 0.57 for Level 1 variance indicate that $34 \%$ of the variance is within-person variance (see Table 6, Model 1). Sleep latency's obtained estimates of 29.27 on Level 2, and 173.07 on Level 1 variance yielded $14.5 \%$ within-person variance (see Table 6, Model 3). Lastly, sleep duration showed estimates of 0 for Level 2 and 23,399.76 for Level 1 variance, suggesting that $0 \%$ of the variance is withinperson variance (see Table 6, Model 5).

Multilevel analyses of the multiple predictor model showed that daily time pressure $(\gamma=-0.25, \mathrm{p}<0.05$; see Table 6, Model 2) as well as social stressors $(\gamma=0.43$, $p<0.01$; see Table 6, Model 2) predicted sleep fragmentation the upcoming night. Partial support was found for hypothesis 3 , as daily social stressors negatively predicted sleep duration the following night $(\gamma=-52.94, p<0.05$; see Table 6, Model 6). No predicting effects were found for sleep latency, yielding no support for hypothesis 2 . Contrary to our expectations, daily social stressors at work did not moderate time pressure's impact on sleep fragmentation $(\gamma=0.05$, ns.; see Table 6, Model 2), sleep latency $(\gamma=-0.85$, ns.; see Table 6 , Model 4), or sleep duration $(\gamma=-34.35$, ns.; see Table 6, Model 6). Thus, hypotheses 4, 5 and 6 were not supported.

Table 5 Study 3: Descriptive statistics and correlations for the variables

\begin{tabular}{|c|c|c|c|c|c|c|c|c|c|c|}
\hline Variable & $M$ & SD & $N$ & 1 & 2 & 3 & 4 & 5 & 6 & 7 \\
\hline 1. $\mathrm{Sex}^{\mathrm{a}}$ & 1.89 & 0.33 & 9 & & $-0.48 * *$ & $0.21 *$ & 0.05 & $0.23 * *$ & 0.16 & 0.06 \\
\hline 2. $\mathrm{Age}^{\mathrm{b}}$ & 2.56 & 1.13 & 9 & $-0.48 * * *$ & & $-0.67 * *$ & 0.01 & -0.04 & $0.19 *$ & $-0.35^{* *}$ \\
\hline 3. Time pressure & 2.48 & 1.02 & 69 & 0.16 & $-0.42 * * *$ & & $0.40 * *$ & $0.23 * *$ & $0.35^{* *}$ & $0.44 * *$ \\
\hline 4. Social Stressors at work & 1.07 & 0.14 & 69 & 0.03 & -0.00 & $0.31 * *$ & & $0.76^{* *}$ & $0.53 * *$ & $0.39 * *$ \\
\hline 5. Sleep fragmentation & 0.5 & 0.91 & 125 & 0.14 & -0.03 & -0.03 & $0.44 * * *$ & & $0.35^{* *}$ & $0.17 *$ \\
\hline 6. Sleep latency & 14.80 & 14.12 & 125 & 0.03 & -0.16 & 0.23 & 0.02 & 0.09 & & -0.07 \\
\hline 7. Sleep duration & 379.06 & 152.96 & 135 & 0.03 & 0.02 & -0.15 & $-0.41 * * *$ & $0.27 * *$ & 0.09 & \\
\hline
\end{tabular}

Lower Triage $=$ Within-person Correlations

Upper Triage $=$ Between-person Correlations

${ }^{*} p<0.05, * * p<0.01, * * * p<0.001$, two-tailed

${ }^{\mathrm{a}} 2=$ female, $1=$ male

b age ranges: $1=20-30$ years, $2=31-40$ years, $3=41-50$ years, $4=51-60$ years, $5 \geq 60$ years 


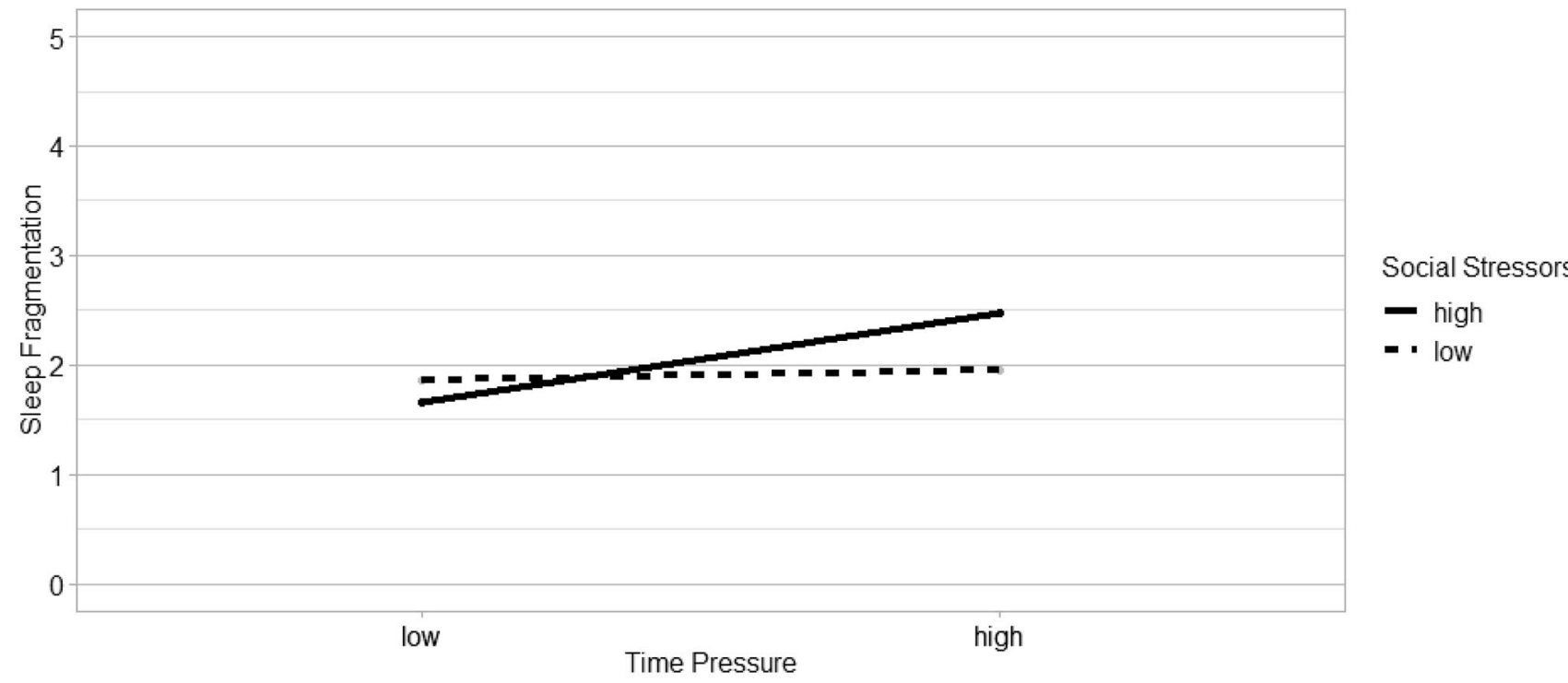

Fig. 2 Moderating Interaction Effect of Social Stressors on the Time Pressure and Sleep Fragmentation Relationship. The Diagram illustrates the effect of time pressure on sleep fragmentation in situations of high vs. low social stressor incidences. Sample size $N=62$ situations

\section{Discussion}

The present research adds to the existing knowledge by uncovering how occupational stressors simultaneously and interdependently predict sleep in the social work population. By means of three independent samples, generated from cross-sectional, diary and actigraphy research designs, this paper allows for a unique and thorough perspective on the matter.

As anticipated (H1), multilevel regression analyses (Studies 2 and 3 ) found that daily time pressure predicted higher sleep fragmentation levels. Study 3 gave further support for Hypothesis 1 and 3, revealing daily social stressors to positively predict sleep fragmentation $(\mathrm{H} 1)$ and negatively sleep duration (H3). Cross-sectional analysis (i.e., study 1) yielded no support for the multiple predictor models $(\mathrm{H} 1-\mathrm{H} 3)$. In regard to the moderating interaction effect, study 1 found social stressors to significantly amplify the effects of time pressure on difficulties falling asleep (i.e., sleep latency), while study 2 found this moderating effect on sleep fragmentation. Study 3, measuring sleep quality with actigraphy, yielded no support for Hypotheses 4-6. Our results provide further empirical evidence that daily time pressure and social stressors are harmful predictors of sleep quality parameters.

Similar to study 3 , prior ambulatory studies found daily social stressors to positively predict sleep fragmentation [15, 21, 23] and negatively sleep duration [52]. Yet, our investigation surpassed these previous inspections by having inferred on a sample of a complete social service unit, thus avoiding a sampling bias [37]. The findings in regard to sleep duration are especially interesting, as prior studies not always yielded significant associations [21].

Theoretically, these results are supported. Social stressors are considered potent job demands due to their threat to positive social relations and self-esteem $[12,53]$. Such short-term allostatic load reactions may prevail and become challenging to stabilize $[19,20]$. This prevalent psychophysiological activation contradicts the main characteristic of sleep, namely psychophysiological deactivation [18], and thus sleep fragmentation is more likely and the duration of sleep is reduced.

Regarding the predicting effects of time pressure on sleep indicators, the present studies yielded no consensus. Sleep fragmentation seemed to be the only sleep parameter affected by daily time pressure. As predicted, study 2 found daily time pressure to positively predict sleep fragmentation the upcoming night; however, in study 3 this association was negative. The cross-sectional analysis (i.e., study 1), on the other hand, did not find significant results for both predictors on all sleep parameters.

From a theoretical perspective, the positive prediction, yielded in study 2, was to be expected. Daily time pressure ignites physiological and psychological arousal, which, as previously explained, is incongruent with the rather relaxed state of sleep [18, 22]; thus sleep awakenings during the night become likely. Also, time pressure's short-term allostatic load reactions may prevail [19, 20], due to cognitions (e.g., worrying or rumination). In other words, the effects of time pressure are prolonged, as employees cognitively 'keep the stressors alive', thus inhibiting recovery processes such as sleep to set in [22]. 


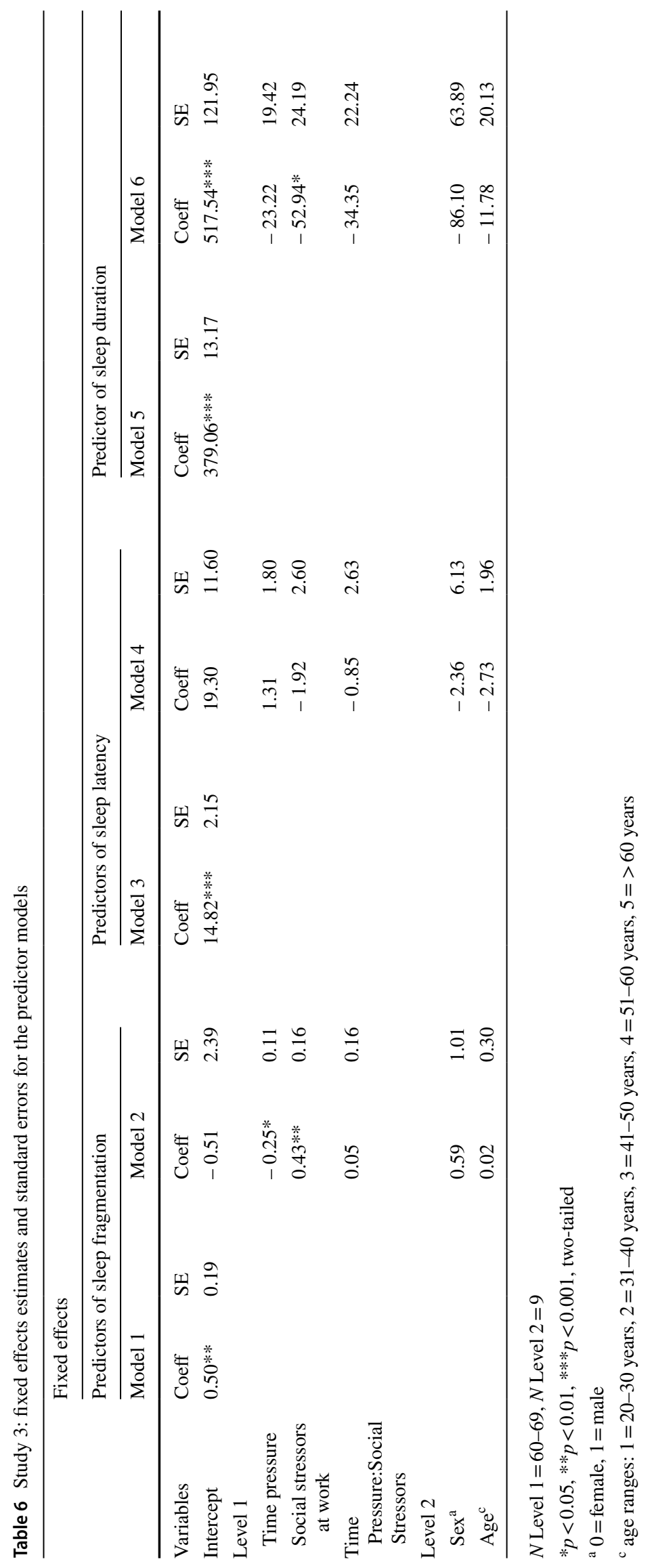


However, as previously mentioned, our findings are contradictory to a certain extent. This is because study 3 revealed an unexpected result $(\mathrm{H} 1)$, namely that daily time pressure experiences were related to less sleep fragmentation. In fact, there is a theoretical explanation for these findings too. Different to social stressors, time pressure may be highly taxing and exhausting for employees [54]. This exhaustion involves psychophysiological deactivation (e.g., fatigue), which is the main characteristic of sleep [18]. Thus, it can be expected that the need for sleep and tiredness, due to taxing time pressure, makes good sleep more likely and sleep awakenings less likely [55]. Another explanation for the negative relationship between time pressure and sleep fragmentation is the COR model [56]. Individuals require the personal and environmental capacity to invest in daily pressure instances [57]. However, this capacity is often threatened as time pressure consumes resources [57]. Through sleep health training and educational modules, employees can actively learn and utilize strategies to induce fewer sleep fragmentations $[58,59]$ to reestablish homeostasis and recover resources $[20,56]$. Such beneficial effects of sleep on employees with low capacity (e.g., exhaustion) have repeatedly been verified [60].

Evidently, the present investigation was unable to gain a consensus answer, as to how time pressure is related to sleep impairments. The reason for this may be, as time pressure's effects on sleep may be highly interdependent of other occupational stressors and factors.

Sonnentag [17] emphasizes the importance of uncovering the interdependency effects of job stressors when investigating sleep impairments; specifically, as a means to tackle the recovery paradox. Following up on this research recommendation, the present study hypothesized, that social stressors will moderate the impact of time pressure on the sleep parameter indicators (Hypotheses 4-6). Cross-sectional analysis (i.e., study 1) indeed revealed a positive moderating effect on sleep latency, while study 2 found social stressors to positively moderate time pressure's effect on sleep disturbances (i.e., sleep fragmentation).

Berset et al. [22] had already revealed that time pressure's effects do not always directly impact sleep parameters, but sometimes only become a threat to sleep under the influence of mediators (e.g., rumination). This is not surprising, as time pressure alone has the potential to yield positive results (e.g., motivate the employee); thus, shortcomings may only arise if other stressors magnify the impact of time pressure. Schmitt et al. [30] support this notion, having found that the relationship between time pressure and work engagement is dependent on the level of illegitimate tasks (i.e., social stressors) being faced by employees. This stands in line with the present findings, namely that social stressors are such potent occupational demands (e.g., threats to social relations and a positive self-image $[12,13])$, that they amplify time pressures effects on difficulties falling asleep as well as sleep fragmentation. Theoretically speaking, recovery from psychophysiological arousal of time pressure alone may still be manageable for employees; yet, adding social stressor to the mix increases and elongates these allostatic load reactions further, and thus prevents the main characteristic of sleep to set in, namely deactivation $[18,19,22]$. If time pressure is accompanied by social stressors, there is also a heightened chance that allostatic load reactions are re-activated or drawn out by cognitions (e.g., rumination), thus inhibiting sleep latency or disturbing sleep [22].

Until now, only a few studies [e.g., 30, 31] have investigated the moderating role of social stressors within complex stress processes. Scholars of various fields of science (e.g., biology) have highlighted the importance of understanding and ultimately predicting interdependencies between stressors [61]. With the present study, we recognized and met this interdisciplinary demand for multiple-stressor research, by showing that the interdependency of various job stressors explains the development of sleep impairments. Furthermore, it became clear that social stressors own characteristics make it a particularly powerful moderator; meaning future research should consider which other job stressors' effects are triggered by the presence of social stressors.

\subsection{Study Advantages and Limitations}

A significant strength of the present study is its appliance of various distinctive samples to investigate the research questions at hand. A cross-sectional investigation (i.e., study 1) gave a comprehensive overview of how social stressors and time pressure are related to sleep quality in this workforce. Studies 2 and 3 allowed us to reveal the direction of withinsubject changes and uncover day-to-day stress processes in social workers. The positive asset of study 3 was that it avoided issues of common-method and sampling bias, by applying a mixed-method design (i.e., diary and actigraphy) and including a sample of a complete social service unit [37].

However, some limitations should be noted as well. Studies 1 and 2 did not use the same self-report scales for the assessment of sleep quality parameters; future studies are advised to apply the same instruments to enable a more valid comparison of findings. In regard to study 3 , the small sample size of nine participants infers limited power and, thus, the risk of missing significant effects in all sleep parameters. Therefore, replication of this pilot study, involving re-sampling, is highly recommended. Furthermore, actigraphy data's validity and reliability may still be questioned [23]. Various studies yielded reliable results from actigraphy methods [i.e., 21]. However, the SenseWear actigraphy methodology would benefit from further validation in naturalistic settings [36]. 


\subsection{Practical Implications and Conclusion}

The present study strategically inferred on three distinctive samples from the social work sector and, by doing so, exposed on various empirical levels (i.e., cross-sectional, and multilevel analysis) that social stressors and time pressure simultaneously and interdependently hamper sleep quality. Additionally, our investigation was one of the first to identify time pressure as a driver of sleep impairments, especially in sequence with social stressors. Educational curriculums and social service organizations are encouraged to take these empirical findings seriously and invest in sleep health training to guarantee staff health and certify high-standard social services to clients.

Author contributions All authors contributed to the study conception and design. Material preparations and data collections were performed by all authors. Data analyses were performed by AE and AE. The first draft of the manuscript was written by AE and all authors commented on previous versions of the manuscript.

Funding Open access funding provided by University of Bern. No funding was received for conducting this study.

Data availability The datasets generated during and/or analyzed during the current study are available from the corresponding author on reasonable request.

\section{Declarations}

Conflicts of interest/Competing interests The authors have no conflicts of interest to declare that are relevant to the content of this article.

Ethics approval This study was performed in line with the principles of the Declaration of Helsinki. Approval was granted by the Ethics Committee of University Bern (Date. $15^{\text {th }}$ August 2010/No. 2010-0800003).

Open Access This article is licensed under a Creative Commons Attribution 4.0 International License, which permits use, sharing, adaptation, distribution and reproduction in any medium or format, as long as you give appropriate credit to the original author(s) and the source, provide a link to the Creative Commons licence, and indicate if changes were made. The images or other third party material in this article are included in the article's Creative Commons licence, unless indicated otherwise in a credit line to the material. If material is not included in the article's Creative Commons licence and your intended use is not permitted by statutory regulation or exceeds the permitted use, you will need to obtain permission directly from the copyright holder. To view a copy of this licence, visit http://creativecommons.org/licenses/by/4.0/.

\section{References}

1. Black JM. Sleep. In: Franklin C, editor. Encyclopedia of social work. Washington: National Association of Social Workers Press and Oxford University Press; 2014.
2. Wolfson M, Germain A. We Snooze, clients lose: time for social workers to join sleep promotion efforts. Soc Work. 2019. https:// doi.org/10.1093/sw/swz021.

3. Cummings C, Singer J, Moody SA, Benuto LT. Coping and work-related stress reactions in protective services workers. $\mathrm{Br}$ J Soc Work. 2019. https://doi.org/10.1093/bjsw/bcz082.

4. Ravalier JM, McFadden P, Boichat C, Clabburn O, Moriarty J. Social worker well-being: a large mixed-methods study. Br J Soc Work. 2021. https://doi.org/10.1093/bjsw/bcaa078.

5. Ohly S, Fritz C. Work characteristics, challenge appraisal, creativity, and proactive behavior: A multi-level study. J Organiz Behav. 2010. https://doi.org/10.1002/job.633.

6. van Heugten K. Social work under pressure: how to overcome stress, fatigue and burnout in the workplace. London: Jessica Kingsley Publishers; 2011.

7. Kühnel J, Sonnentag S, Bledow R. Resources and time pressure as day-level antecedents of work engagement. J Occup Organ Psychol. 2012. https://doi.org/10.1111/j.2044-8325.2011.02022.x.

8. Kleiner S, Wallace JE. Oncologist burnout and compassion fatigue: investigating time pressure at work as a predictor and the mediating role of work-family conflict. BMC Health Serv Res. 2017. https://doi.org/10.1186/s12913-017-2581-9.

9. Skaalvik EM, Skaalvik S. Teacher job satisfaction and motivation to leave the teaching profession: relations with school context, feeling of belonging, and emotional exhaustion. Teach Teacher Educ. 2011. https://doi.org/10.1016/j.tate.2011.04.001.

10. Dormann C, Zapf D. Social stressors at work, irritation, and depressive symptoms: accounting for unmeasured third variables in a multi-wave study. J Occup Organ Psychol. 2002. https://doi. org/10.1348/096317902167630.

11. Dormann C, Zapf D. Customer-related social stressors and burnout. J Occup Health Psychol. 2004. https://doi.org/10.1037/10768998.9.1.61.

12. Semmer NK, Jacobshagen N, Meier L, Elfering A. Occupational stress research: the Stress-As-Offense-To-Self Perspective. In: McIntyre S, Houdmont J, editors. Occupational health psychology: European perspectives on research, education and practice. ISMAI Publishing; 2007. pp. 41-58.

13. Semmer NK, Tschan F, Jacobshagen N, Beehr TA, Elfering A, Kälin W, Meier LL. Stress as offense to self: a promising approach comes of age. Occup Health Sci. 2019. https://doi.org/10.1007/ s41542-019-00041-5.

14. Pereira D, Mueller P, Elfering A. Workflow interruptions, social stressors from supervisor(s) and attention failure in surgery personnel. Ind Health. 2015. https://doi.org/10.2486/indhealth. 2013-0219.

15. Pereira D, Elfering A. Social stressors at work, sleep quality and psychosomatic health complaints-a longitudinal ambulatory field study. Appl Psychophysiol Biofeedback. 2014. https://doi. org/10.1002/smi.2494.

16. Eggli A, Romano-Pereira D, Elfering A. Short-term effects of social stressors at work on rumination and physical symptoms in social workers. Ind Health. 2021. https://doi.org/10.2486/indhe alth.2020-0192.

17. Sonnentag $\mathrm{S}$. The recovery paradox: portraying the complex interplay between job stressors, lack of recovery, and poor well-being. Res Organ Behav. 2018. https://doi.org/10.1016/j.riob.2018.11. 002.

18. Åkerstedt T. Psychosocial stress and impaired sleep. Scand J Work Environ Health. 2006;326:493-501.

19. Meijman TF, Mulder G. Psychological aspects of workload. In: Drenth PJD, Thierry H, de Wolff CJ, editors. Handbook of work and organizational psychology: work psychology. UK: Psychology Press/Erlbaum: Taylor \& Francis; 1998. pp. 5-33. 
20. McEwen BS. Sleep deprivation as a neurobiologic and physiologic stressor: allostasis and allostatic load. Metabolism. 2006. https:// doi.org/10.1016/j.metabol.2006.07.008.

21. Pereira D, Gross S, Elfering A. Social stressors at work, sleep, and recovery. Appl Psychophysiol Biofeedback. 2016. https://doi.org/ 10.1007/s10484-015-9317-6.

22. Berset M, Elfering A, Lüthy S, Lüthi S, Semmer NK. Work stressors and impaired sleep: rumination as a mediator. Stress Health. 2011. https://doi.org/10.1002/smi.1337.

23. Pereira D, Meier LL, Elfering A. Short-term effects of social exclusion at work and worries on sleep. Stress Health. 2013. https://doi.org/10.1002/smi.2461.

24. Vleeshouwers J, Knardahl S, Christensen JO. Effects of psychological and social work factors on self-reported sleep disturbance and difficulties initiating sleep. Sleep. 2016. https://doi.org/10. 5665/sleep.5638.

25. Tavernier R, Willoughby T. A longitudinal examination of the bidirectional association between sleep problems and social ties at university: the mediating role of emotion regulation. J Youth Adolesc. 2015. https://doi.org/10.1007/s10964-014-0107-x.

26. Kent RG, Uchino BN, Cribbet MR, Bowen K, Smith TW. Social relationships and sleep quality. Ann Behav Med. 2015. https://doi. org/10.1007/s12160-015-9711-6.

27. Rabei S, Mourad G, Hamed AED. Work stress and sleep disturbances among internship nursing students. Middle East Curr Psychiatry. 2020. https://doi.org/10.1186/s43045-020-00032-1.

28. Barck-Holst P, Nilsonne Å, Ảkerstedt T, Hellgren C. Reduced working hours and stress in the Swedish social services: a longitudinal study. Int Soc Work. 2017. https://doi.org/10.1177/00208 72815580045.

29. Åkerstedt T, Olsson B, Ingre M, Holmgren M, Kecklund G. A 6-hour working day-effects on health and well-being. J Hum Ergol. 2001. https://doi.org/10.11183/jhe1972.30.197.

30. Schmitt A, Ohly S, Kleespies N. Time pressure promotes work engagement. J Pers Psychol. 2015. https://doi.org/10.1027/18665888/a000119.

31. Zhou ZE, Eatough EM, Wald DR. Feeling insulted? Examining end-of-work anger as a mediator in the relationship between daily illegitimate tasks and next-day CWB. J Organiz Behav. 2018. https://doi.org/10.1002/job.2266.

32. Sonnentag S, Binnewies C, Mojza EJ. "Did you have a nice evening?" A day-level study on recovery experiences, sleep, and affect. J Appl Psychol. 2008;393:674-84.

33. Jung CM, Melanson EL, Frydendall EJ, Perreault L, Eckel RH, Wright KP. Energy expenditure during sleep, sleep deprivation and sleep following sleep deprivation in adult humans. J Physiol. 2011. https://doi.org/10.1113/jphysiol.2010.197517.

34. Barone DA, Krieger AC. The function of sleep. AIMS Neurosci. 2015. https://doi.org/10.3934/Neuroscience.2015.2.71.

35. Podsakoff PM, MacKenzie SB, Lee JY, Podsakoff NP. Common method biases in behavioral research: a critical review of the literature and recommended remedies. J Appl Psychol. 2003. https:// doi.org/10.1037/0021-9010.88.5.879.

36. Pereira D, Semmer NK, Elfering A. Illegitimate tasks and sleep quality: an ambulatory study. Stress Health. 2014. https://doi.org/ 10.1002/smi.2599.

37. Kottwitz MU, Lachapelle M, Elfering A. Time pressure, social work stressors and blood pressure in a team of seven it-workers during one week of intense work. Int J Psychol. 2014;14:51-69.

38. Wesensten NJ, Balkin TJ, Belenky G. Does sleep fragmentation impact recuperation? A review and reanalysis. J Sleep Res. 1999. https://doi.org/10.1046/j.1365-2869.1999.00161.x.

39. Galliker S, Igic I, Elfering A, Semmer NK, Brunner B, Dosch S, Wieser S. Job-Stress-Index 2020. Survey of key figures on mental health and stress among employed persons in Switzerland. Kommentierter Tabellenband: Universität Bern; 2020.
40. Maas CJM, Hox JJ. Sufficient Sample Sizes for Multilevel Modeling. Methodol. 2005. https://doi.org/10.1027/1614-2241.1.3.86.

41. Frese M, Zapf D. Eine Skala zur Erfassung von sozialen Stressoren am Arbeitsplatz. Zeitschrift für Arbeitswissenschaft. 1987;41:134-41.

42. Semmer NK, Zapf D, Dunckel H. Assessing stress at work: a framework and an instrument. Luxembourg: Office for Offical Publications of the European Communities; 1995.

43. Irmer JP, Kern M, Schermelleh-Engel K, Semmer NK, Zapf D. The Instrument for Stress-Oriented Task Analysis (ISTA). Z Arbeits- und Org A\&O. 2019. https://doi.org/10.1026/0932-4089/ a000312.

44. Bastien C. Validation of the Insomnia Severity Index as an outcome measure for insomnia research. Sleep Med. 2001. https:// doi.org/10.1016/S1389-9457(00)00065-4.

45. Åkerstedt T, Knutsson A, Westerholm P, Theorell T, Alfredsson L, Kecklund G. Sleep disturbances, work stress and work hours. J Psychosom Res. 2002. https://doi.org/10.1016/S0022-3999(02) 00333-1.

46. Buysse DJ, Reynolds CF, Monk TH, Berman SR, Kupfer DJ. The Pittsburgh sleep quality index: A new instrument for psychiatric practice and research. Psychiatry Res. 1989. https://doi.org/10. 1016/0165-1781(89)90047-4.

47. Sunseri M, Liden CB, Farringdon J, Pelletier R, Safier S, Stivoric J, Teller A, Vishnubhatla S. The Sensewear Armband as a sleep detection device. BodyMedia internal white paper. 2009:1-9.

48. van Wouwe NC, Valk PJL, Veenstra BJ. Sleep monitoring: a comparison between three wearable instruments. Mil Med. 2011. https://doi.org/10.7205/milmed-d-10-00389.

49. The R Project for Statistical Computing; 2020.

50. IBM Spss Statistics for Windows. Armonk. NY: IBM Corp; 2020.

51. Nezlek JB. Multilevel random coefficient analyses of event- and interval-contingent data in social and personality psychology research. Pers Soc Psychol Bull. 2001. https://doi.org/10.1177/ 0146167201277001.

52. Pereira D, Elfering A. Social stressors at work and sleep during weekends: the mediating role of psychological detachment. J Occup Health Psychol. 2014. https://doi.org/10.1037/a0034928.

53. Baumeister RF, Leary MR. The need to belong: desire for interpersonal attachments as a fundamental human motivation. Psychol Bull. 1995. https://doi.org/10.1037/0033-2909.117.3.497.

54. Teuchmann K, Totterdell P, Parker SK. Rushed, unhappy, and drained: an experience sampling study of relations between time pressure, perceived control, mood, and emotional exhaustion in a group of accountants. J Occup Health Psychol. 1999. https://doi. org/10.1037/1076-8998.4.1.37.

55. Lavidor $\mathrm{M}$, Weller $\mathrm{A}, \mathrm{Babkoff} \mathrm{H}$. How sleep is related to fatigue. Br J Health Psychol. 2003. https://doi.org/10.1348/1359107037 62879237

56. Hobfoll SE. Conservation of resources: a new attempt at conceptualizing stress. Am Psychol. 1989;443:513-24.

57. Sheng X, Wang Y, Hong W, Zhu Z, Zhang X. The curvilinear relationship between daily time pressure and work engagement: The role of psychological capital and sleep. Int J Stress Manag. 2019. https://doi.org/10.1037/str0000085.

58. Barber L, Grawitch MJ, Munz DC. Are better sleepers more engaged workers? A self-regulatory approach to sleep hygiene and work engagement. Stress Health. 2013. https://doi.org/10. 1002/smi.2468.

59. Spadola C, Groton D, Lopez R, Burke SL, Hilditch CJ, Pandey A, Littlewood K, Zhou ES, Bertisch SM. Preliminary impact of a sleep health educational module for social work students. Sleep. 2020. https://doi.org/10.1093/sleep/zsaa056.1163.

60. Murnieks CY, Arthurs JD, Cardon MS, Farah N, Stornelli J, Michael HJ. Close your eyes or open your mind: effects of sleep 
and mindfulness exercises on entrepreneurs' exhaustion. J Bus Ventur. 2020. https://doi.org/10.1016/j.jbusvent.2018.12.004.

61. Orr JA, Vinebrooke RD, Jackson MC, Kroeker KJ, Kordas RL, Mantyka-Pringle C, van den Brink PJ, De Laender F, Stoks R, Holmstrup M, Matthaei CD. Towards a unified study of multiple stressors: divisions and common goals across research disciplines. Proc Biol Sci. 2020. https://doi.org/10.1098/rspb.2020.0421.

Publisher's Note Springer Nature remains neutral with regard to jurisdictional claims in published maps and institutional affiliations. 